\title{
$\beta$-Nucleation of isotactic polypropylene: Chain structure effects on the effectiveness of two different nucleating agents
}

\author{
J. Wang, M. Gahleitner* , D. Gloger, K. Bernreitner \\ Borealis Polyolefine GmbH, Innovation Headquarters, St. Peterstr. 25, 4021 Linz, Austria
}

Received 23 September 2019; accepted in revised form 20 January 2020

\begin{abstract}
Of all crystal modifications of isotactic polypropylene (iPP), the $\beta$-phase has received particular attention in both academia and industry because of the toughness increase resulting from its formation. Several novel nucleating agents have been presented and studied in recent years, most prominently the 'lanthanum complex' WBG. The majority of these studies are based only on one type of iPP, mostly an iPP homopolymer, despite the fact that chain irregularities are known to affect $\beta$-phase formation negatively. In the present study, several different iPP homo- and copolymers based on Ziegler-Natta and single-site catalysts differing mostly in chain defect concentration were used to evaluate the sensitivity of a 'reference' nucleating agent, quinacridonequinone, as well as WBG to chain structure effects. The results in terms of crystal structure, as well as mechanics, indicate a much greater sensitivity of WBG, resulting in a massively reduced $\beta$-phase formation for SSCiPP hompolymers and ZN-iPP random copolymers with ethylene. An increase of $\gamma$-phase content in nucleation of the polymers with least regular chain structure hints at some duality for WBG as also observed for other $\beta$-nucleating agents before.
\end{abstract}

Keywords: mechanical properties, polypropylene, crystallization, nucleation, chain structure

\section{Introduction}

Controlling the crystalline morphology through variations of polymer, nucleating agent, and processing is one of the key factors in designing the mechanical performance of polymers [1]. For isotactic polypropylene (iPP), one of the commercially and technically most important semi-crystalline polymers with a global production volume of more than 70 million tons, its polymorphism has been found to be an important design parameter when adapting the material to market requirements [2]. Among the various crystal modifications, nowadays ranging from $\alpha$ to $\delta$, the $\beta$-modification has always played an especially important role. $\beta$-iPP derives its fascination partly from the special 'frustrated' crystal structure, originally discovered and recently extensively discussed by Lotz and coworkers [3, 4], partly from the fact that it offers advantageous mechanical performance.
When Grein [5] published her extensive review on $\beta$-iPP, it appeared that there was not very much more to be learned on the formation and performance of this industrially highly relevant modification. Like with other polymorphs of iPP, expression and stability are determined by polymer structure and thermal history, but more than for the $\alpha$ - or $\gamma$-form, the selection of a nucleating agent is decisive [6]. In this respect, some new developments have been covered by numerous, mostly Chinese, working groups in recent years.

The most relevant and frequently used novel $\beta$-nucleating agent is WBG or WBG-II, mostly described as 'rare earth complex' or 'lanthanum complex', somewhat more precisely by the sum formula $\mathrm{Ca}_{\mathrm{x}} \mathrm{La}_{1-\mathrm{x}}(\mathrm{LIG1})_{\mathrm{m}}(\mathrm{LIG} 2)_{\mathrm{n}}$ with LIG1 and LIG2 being organic ligands [7]. This paper of Liu et al. is just one of the most recent examples in a long row of

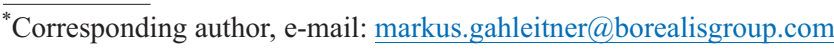
C BME-PT 
publications on the application of WBG. Several working groups evaluated the performance of this $\beta$-nucleating agent alone [7-13], varying dispersion mode, cooling history, and base polymer type. Comparisons to $\alpha$-nucleation [14-18] or other types of $\beta$-nucleating agents were done as well. The latter was done in comparison to DCHT $\left(N, N^{\prime}\right.$-dicyclohexyl-terephthalamide) by Xiao et al. [19] and Fu et al. [20]. DCHT had originally been commercialized as NU-100 by New Japan Chemical and appears to be available as TMB5 from Chinese suppliers now. The capability of DCHT to induce either $\beta$ - or $\alpha$ phase formation, depending on the respective thermal history, has been studied extensively by Varga and Menyhárd [21] and limits its industrial applicability. Despite this problem, DCHT has been used in several other studies, both before [22, 23] and after [24-31] the discoveries of Varga and Menyhárd, including studies of processing effects [32]. Quite recently, combined effects of DCHT nucleation and glass fiber (GF) reinforcement have been studied [33], finding a better performance than in combination of GF and $\alpha$-nucleation [34]. This combination has, however, already been shown to be effective before, mostly because of an interlayer formation around the fiber $[35,36]$.

Two further earlier tested $\beta$-nucleating agents, $\gamma$-quinacridone and Ca-pimelate, are well discussed in the review of Grein [5] and also continuously receiving attention. The former mostly applied as commercial pigment mixture Cinquasia red, is in industrial use since the 1970s and has accordingly been studied before, including modifications of the composition [37, 38]. More recent work has been done in terms of cooling rate effect $[2,39]$ and other processing-related phenomena [40, 41]. The latter, having the advantage of being both colorless and highly efficient in a wide range of iPP types [42, 43], showed some difficulties in market introduction. A very recent paper of Yue et al. [44] dealing with the effect of thermal treatment on the $\beta$-nucleation efficiency of Ca-pimelate sheds some light on the effects of drying and storage of this substance, which we also experienced in our group before (unpublished data). The effects of base polymer structure and cooling rate $[45,46]$ appear to be similar to other types, while the possibility of facilitating handling and dispersion by supporting on calcium carbonate micro- or nanoparticles [47] appears to be unique.
A number of research groups have also studied more 'exotic' types of $\beta$-nucleating agents. At Budapest, Horváth et al. [48] did an extensive molecular weight series with Ca-suberate discovered several years before in the same group [49], while Varga et al. [50] tested a trisamide of trimesic acid, obviously soluble in melt state like most of the trisamides evaluated as clarifiers for $\alpha$-nucleation [7]. Chinese groups have studied the liquid-crystalline polyester PBDPS [51], zinc adipate [52], alkaline salts of 7-oxabicyclo[2,2,1] hept-5-ene-2,3-dicarboxylic acid [53], chromium salt of bicyclo[2,2,1]-5-heptene-2,3-dicarcoxylic acid [54] and most recently polydopamine (PDAP) [55]. In most of the mentioned more recent papers, only one type of iPP has been used for the studies, mostly an iPP homopolymer based on a Ziegler-Natta (ZN) type catalyst. These polymers are mostly highly isotactic, and values of pentad regularity based on ${ }^{13} \mathrm{C}-\mathrm{NMR}$ spectroscopy $(\mathrm{mmmm})$ in the range of $91.8 \%$ [45] to $98 \%$ [18] are reported. In the absence of method details, however, the degree of comparability of these isotacticity values remains unclear, and only one paper actually compares ZN-based iPP homopolymers of different isotacticity [46]. Other chain regularity measures like the 'isotactic index' based on solubility [24] are even more difficult to compare. Stronger reductions of chain regularity and, subsequently, crystallization speed as well as crystallinity are achievable for $\mathrm{ZN}$-iPP by copolymerization with ethylene $[56,57]$ or higher $\alpha$-olefins like butene or hexene $[58,59]$. At least for propyleneethylene random copolymers, a significant negative effect of the less regular chain structure on $\beta$-phase formation was already found by Varga and SchulekTóth [60] as well as Fujiyama [61], and quantified in the review of Grein [5]. More recent work confirms this effect in direct comparison [11], and it has been found to be even more significant at higher cooling rates [2].

iPP homopolymers based on single-site catalysts (SSC) like metallocenes (MC) can have very high isotacticity, but their chain regularity is also reduced by regiodefects resulting from misinsertions of monomer units. Especially without nucleation, such grades exhibit slower crystallization resulting from the combined effect of chain structure on growth rate and narrower molecular weight distribution (MWD) on nucleation density [62]. The effect of these changes on $\beta$-nucleation of SSC-iPP has only been studied in 
few cases so far $[22,23,45]$. Even if a full quantification is missing in two of these papers, one can conclude that regiodefects are reducing $\beta$-phase formation more than stereodefects, but probably less than ethylene units. The direct comparison of a SSC-iPP with a pentad isotacticity of $94.3 \%$ and a content of regiodefects of $0.89 \%$ with a $\mathrm{ZN}-\mathrm{iPP}$ with $91.8 \%$ isotacticity and no regiodefects with DCHT as $\beta$-nucleating agent resulted in a $\beta$-phase content of $71 \%$ for the SSC-iPP as compared to $91 \%$ for the $\mathrm{ZN}-\mathrm{iPP}$ (slow cooling, crystal modifications determined by wide-angle X-ray scattering, WAXS).

In contrast to random copolymers, the disperse elastomer phase of heterophasic copolymers of iPP having a homopolymer matrix [63] does not affect the formation of $\beta$-phase negatively. The resulting mechanical performance, especially the toughness increase, will, however, depend strongly on elastomer phase content and structure $[4,43]$. A similar statement can be made for molecular weight effects, which have again mostly been studied for homopolymers. The melt flow rate (MFR) series studied by Horváth et al. [48] ranges from 0.2 to $89 \mathrm{~g} / 10 \mathrm{~min}$ (at $230^{\circ} \mathrm{C}$ and $2.16 \mathrm{~kg}$ load) and finds a minor variation of $\beta$-phase content between 98.3 and $99.4 \%$ for slowly cooled samples nucleated with Ca-suberate. Mechanical performance was not checked in this work, but in several earlier papers $[5,42]$ the massively negative effect of decreasing molecular weight on impact strength improvement has been documented and discussed.

In none of the papers cited so far, the combined effects of iPP chain structure, in detail the concentration of chain defects resulting from catalyst and comonomer, and nucleating agent type have been studied. Knowing the variation of $\beta$-nucleation efficiency as a function of chain regularity for different nucleating agnet types is, however, very important for property-oriented composition design in industrial practice. We, therefore, conducted a study with several different iPP homo- and copolymers based on Ziegler-Natta and single-site catalysts to evaluate the sensitivity of a 'reference' nucleating agent, quinacridonequinone, as well as WBG to chain structure effects. The results presented here indicate a much greater sensitivity of WBG, resulting in a massively reduced $\beta$-phase formation for SSC-iPP hompolymers and ZN-iPP random copolymers with ethylene.

\section{Experimental work}

Two ZN-iPP hompopolymer powders from commercial production having different MFR, one SSC-iPP homopolymer based on a proprietary metallocene catalyst, and two $\mathrm{ZN}-\mathrm{iPP}$ random copolymers with different ethylene content were selected for the study. We based the election on the overall concentration of chain defects resulting from catalyst (i.e. stereo- and regiodefects) and comonomer (i.e. ethylene units). The key characteristics of the polymers are listed in Table 1. PP-H1 comes from a diluentslurry process involving multiple stirred tank reactors and is based on a $2^{\text {nd }}$ generation $\mathrm{ZN} 1$ catalyst with methyl-methacrylate as external donor. The ZN2 catalyst used for PP-H2 as well as for the random copolymers, PP-R1 and PP-R2, was a self-supported type from an emulsion process as described before [64], but with a non-phthalate internal donor and combined with dicyclopentyl dimethoxy silane (donor D) as external donor. The SSC used for PP$\mathrm{H} 3$ is an asymmetric metallocene catalyst similarly heterogenized in an emulsion process. Pilot- or fullscale polymerization units of the Borstar PP process, combining liquid- and gas-phase reactors, were used for polymerization of all polymers except PP-H1.

Table 1. Molecular characteristics of the selected base polymers.

\begin{tabular}{|c|c|c|c|c|c|c|}
\hline \multicolumn{2}{|c|}{ Polymer } & PP-H1 & PP-H2 & PP-H3 & PP-R1 & PP-R2 \\
\hline Catalyst & & ZN1 & ZN2 & SSC & ZN2 & ZN2 \\
\hline $\mathrm{C} 2$ & {$[\mathrm{wt} \%]$} & 0 & 0 & 0 & 3.1 & 2.2 \\
\hline $\mathrm{mmmm}$ & {$[\mathrm{mol} \%]$} & 93.1 & 95.2 & 99.5 & n.d. & n.d. \\
\hline$<2,1>$ regio-defects & [mol\%] & 0 & 0 & 1.0 & n.d. & n.d. \\
\hline MFR & {$[\mathrm{g} / 10 \mathrm{~min}]$} & 2.8 & 0.3 & 0.4 & 1.9 & 2.0 \\
\hline$M_{\mathrm{W}}$ & {$[\mathrm{kg} / \mathrm{mol}]$} & 565 & 1007 & 478 & 596 & 584 \\
\hline$M_{\mathrm{w}} / M_{\mathrm{n}}$ & {$[-]$} & 6.2 & 4.9 & 3.3 & 4.8 & 4.7 \\
\hline $\mathrm{XCS}$ & {$[\mathrm{wt} \%]$} & 2.5 & 2.4 & 0.3 & 5.7 & 4.1 \\
\hline$T_{\mathrm{c}}$ & {$\left[{ }^{\circ} \mathrm{C}\right]$} & 116 & 120 & 115 & 114 & 110 \\
\hline$T_{\mathrm{m}}$ & {$\left[{ }^{\circ} \mathrm{C}\right]$} & 163 & 165 & 152 & 149 & 152 \\
\hline
\end{tabular}


Comonomer (i.e. ethylene, $\mathrm{C} 2$ ) content, as well as isotacticity and regio-defects of the polymers, were determined by ${ }^{13} \mathrm{C}$ nuclear magnetic resonance (NMR) spectroscopy. Quantitative ${ }^{13} \mathrm{C}\left\{{ }^{1} \mathrm{H}\right\}$ NMR spectra were recorded in the solution-state using a Bruker Advance III $400 \mathrm{NMR}$ spectrometer operating at 400.15 and $100.62 \mathrm{MHz}$ for ${ }^{1} \mathrm{H}$ and ${ }^{13} \mathrm{C}$ respectively. All spectra were recorded using a ${ }^{13} \mathrm{C}$ optimized $10 \mathrm{~mm}$ extended temperature probe head at $125^{\circ} \mathrm{C}$ using nitrogen gas for all pneumatics. For iPP homopolymers, approximately $200 \mathrm{mg}$ of material was dissolved in 1,2-tetrachloroethane- $d_{2}$ (TCE- $\left.d_{2}\right)$. To ensure a homogenous solution, after initial sample preparation in a heat block, the NMR tube was further heated in a rotary oven for at least 1 hour. Upon insertion into the magnet the tube was spun at $10 \mathrm{~Hz}$. This setup was chosen primarily for the high resolution needed for tacticity distribution quantification [65]. Standard single-pulse excitation was employed utilizing the NOE and bi-level WALTZ16 decoupling scheme [66]. A total of 8192 (8k) transients were acquired per spectra. The resulting spectra were processed, integrated and relevant quantitative properties determined from the integrals using proprietary computer programs.

For polypropylene homopolymers, all chemical shifts are internally referenced to the methyl isotactic pen$\operatorname{tad}(\mathrm{mmmm})$ at $21.85 \mathrm{ppm}$. The tacticity distribution was quantified through the integration of the methyl region between 23.6-19.7 ppm correcting for any sites not related to the stereo sequences of interest $[65,67]$. Specifically, the influence of regio-defects and comonomer on the quantification of the tacticity distribution was corrected for by subtraction of representative regio-defect and comonomer integrals from the specific integral regions of the stereo sequences. The isotacticity was determined at the pentad level and reported as the percentage of isotactic pentad (mmmm) sequences with respect to all pentad sequences as shown in Equation (1):

$$
[\mathrm{mmmm}] \%=100 \cdot \frac{\mathrm{mmmm}}{\text { sum of all pentads }}
$$

An analogous determination of isotactic pentads is not possible for random copolymers with ethylene, but as these are based on the same catalyst/donor combination, an identical background chain structure can be assumed.

The presence of 2,1-erythro regio defects was indicated by the presence of the two methyl sites at 17.7 and $17.2 \mathrm{ppm}$ and confirmed by other characteristic sites, while characteristic signals corresponding to other types of regio defects were not observed [68]. The amount of 2,1-erythro regio-defects was quantified using the average integral of the two characteristic methyl sites at 17.7 and $17.2 \mathrm{ppm}$, see Equation (2):

$P_{21 \mathrm{e}}=\frac{I_{\mathrm{e} 6}-I_{e 8}}{2}$

The amount of 1,2 primary inserted propene was quantified based on the methyl region with correction undertaken for sites included in this region not related to primary insertion and for primary insertion sites excluded from this region, as shown in Equation (3):

$P_{12}=I_{\mathrm{CH}_{3}}+P_{12 \mathrm{e}}$

The total amount of propene was quantified as the sum of primary inserted propene and all other present regio-defects, see Equation (4):

$P_{\text {total }}=P_{12}+P_{21 \mathrm{e}}$

The mole percentage of 2,1-erythro regio-defects was then quantified with respect to all propene, see Equation (5):

$[21 \mathrm{e}] \mathrm{mol} \%=100 \cdot \frac{P_{21 \mathrm{e}}}{P_{\text {total }}}$

Differential scanning calorimetry (DSC) analysis for non- and $\beta$-nucleated compositions was performed with a Mettler TA Instrument Q2000 on $5 \mathrm{mg}$ samples. DSC was run according to ISO 11357/part 3/method $\mathrm{C} 2$ in a heat/cool/heat cycle with a scan rate of $10^{\circ} \mathrm{C} / \mathrm{min}$ in the temperature range of -30 to $+225^{\circ} \mathrm{C}$. Crystallization temperature $\left(T_{\mathrm{c}}\right)$ was determined from the cooling step, while the melting temperatures $\left(T_{\mathrm{m}}\right)$ and heat of melting $\left(H_{\mathrm{m}}\right)$ were determined from the second heating step. For the samples showing $\beta$-phase content as two separate melting peaks, integration was performed separately and the ratio calculated according to Equation (6):

$\beta_{\mathrm{DSC}}=\frac{H_{\mathrm{m}, 2}}{H_{\mathrm{m}, 1}+H_{\mathrm{m}, 2}}$

with $H_{\mathrm{m}, 1}$ being the enthalpy of the upper $\alpha$-phase peak and $H_{\mathrm{m}, 2}$ the one of the lower $\beta$-phase peak. 
The xylene cold solubles (XCS) content was determined at $25^{\circ} \mathrm{C}$ according to ISO 16152 , first edition 2005.

The standard reference $\beta$-nucleating agent was quinacridonequinone CGNA-7588 (IUPAC name 5,12-dihydroquinolino[2,3-b]acridine-6,7,13,14tetrone, CAS number 1503-48-6; distributed by BASF AG, Germany) designated as 'CGNA' in the tables and shown in Figure 1. In comparison to that, the heteronuclear dimetal complex of lanthanum and calcium (distributed by Guangdong Winner Functional Materials Co., China), was used as an alternative $\beta$-nucleating agent 'WBG'. All polymer powders were melt-stabilized with $0.05 \mathrm{wt} \%$ of $\mathrm{Ca}-$ stearate (CAS Number 1592-23-0) and $0.15 \mathrm{wt} \%$ of Irganox B215 (distributed by BASF AG, Germany), a 1:2-mixture of pentaerythrityl-tetrakis (3-( $3^{\prime}, 5^{\prime}$-ditert. butyl-4-hydroxyphenyl)-propionate (CAS number 6683-19-8) and tris-(2,4-di-t-butylphenyl) phosphite (CAS number 31570-04-4). Compounding was performed on a Coperion ZSK57 twin-screw extruder with a melt temperature of $200-240{ }^{\circ} \mathrm{C}$.

Next to DSC, the overall crystallinity, as well as the distribution of the different polymorphs of iPP, was determined by wide-angle X-ray scattering (WAXS). Samples for WAXS were prepared by compression molding according to ISO 173-2 on a frame mold of $250 \times 250 \times 2 \mathrm{~mm}^{3}$, using a molding temperature of $210^{\circ} \mathrm{C}$ and a pressure of $5 \mathrm{MPa}$, an average cooling rate of $15^{\circ} \mathrm{C} / \mathrm{min}$ and a demolding temperature of $40^{\circ} \mathrm{C}$. The full molding pressure was applied for 5 min. A Bruker D8 Discover apparatus was used for WAXS measurement of the samples, the diffractometer being equipped with an X-ray tube with a copper target operating at $30 \mathrm{kV}$ and $20 \mathrm{~mA}$ and a GADDS 2-D detector. Point collimation $(0.5 \mathrm{~mm})$ was used to direct the beam onto the surface. The measurement was done in reflection geometry, and 28 angles in the range from 10 to $32.5^{\circ}$ were measured. Data were collected for $300 \mathrm{~s}$. An intensity vs. $2 \Theta$ curve was acquired with the same measurement parameters on an amorphous polypropylene sample, which was prepared by solvent extraction. The<smiles>O=C1c2[nH]c3ccccc3c(=O)c2C(=O)c2[nH]c3ccccc3c(=O)c21</smiles>

Figure 1. Chemical structure of quinacridonequinone CGNA-7588.

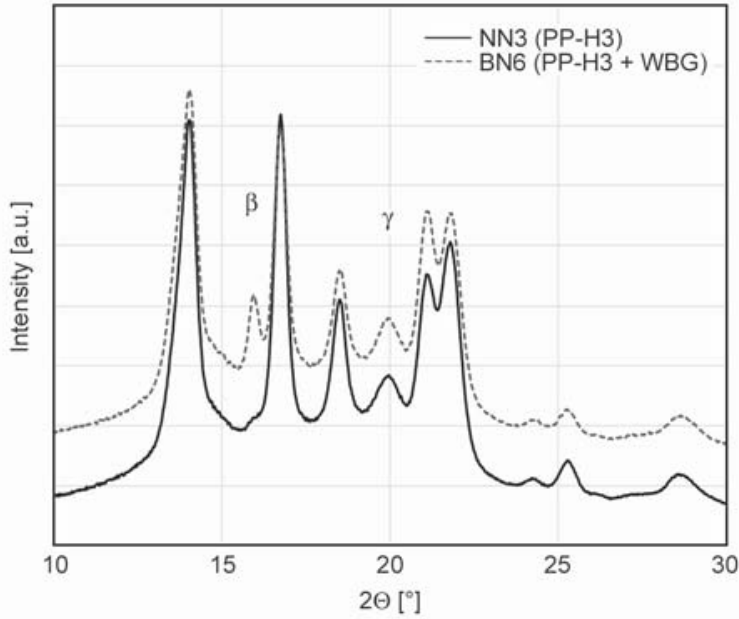

Figure 2. WAXS diffractograms of SSC-based PP homopolymer (PP-H3) and its composition $\beta$-nucleated with WBG (curves shifted on intensity axis to improve comparability).

amorphous halo obtained by smoothing this curve was subtracted from the measured intensity vs. $2 \Theta$ curve to result in the crystalline curve. Examples of the resulting curves are presented in Figure 2.

The crystallinity index $X_{\mathrm{C}}$ can be defined by the area under the crystalline curve and the original spectrum using the method of Challa et al. [69] as shown in Equation (7):

$X_{\mathrm{C}}=\frac{\text { area under crystalline curve }}{\text { area under original spectrum }} \cdot 100$

The amount of $\beta$-form of the polypropylene within the crystalline phase $K_{\beta}$ is calculated using the Turner-Jones method [70] according to the following Equation (8):

$K_{\beta}=\frac{I \beta(300)}{I \alpha(110)+I \alpha(040)+I \alpha(130)+I \beta(300)}$

where, $I \beta(300)$ is the intensity of $\beta(300)$ peak, $I \alpha(110)$ is the intensity of $\alpha(110)$ peak, $I \alpha(040)$ is the intensity of $\alpha(040)$ peak and $I \alpha(130)$ is the intensity of $\alpha(130)$ peak obtained after subtracting the amorphous halo. In the absence of $\beta$-phase, the amount of $\gamma$-form of iPP within the crystalline phase $K_{\gamma}$ may be calculated using the method developed by Pae [71] as shown in Equation (9):

$K_{\gamma}=\frac{I \gamma(117)}{I \alpha(130)+I \gamma(117)}$

where $I \alpha(130)$ is the intensity of $\alpha(130)$ peak and $I \gamma(117)$ is the intensity of $\gamma(117)$ peak obtained after 
subtracting a baseline joining the base of these peaks.

Quantification of the three-phase crystalline system has been carried out following the procedure explained in a paper by Obadal et al. [72]. For threephase crystalline systems, the following Equations (10)-(13) have been used to determine $K_{\alpha}$ (amount of $\alpha$-phase), $K_{\beta}$ (amount of $\beta$-phase) and $K_{\gamma}$ (amount of $\gamma$-phase):

$$
\begin{aligned}
& K_{\beta}= \\
& =\frac{I \beta(300)}{I \alpha(110)+I \alpha(040)+I \alpha(130)+I \beta(300)+I \gamma(117)}
\end{aligned}
$$

$$
\begin{aligned}
& K_{\alpha+\gamma}=1-K_{\beta} \\
& K_{\gamma}=G \cdot K_{\alpha+\gamma}
\end{aligned}
$$

and

$$
K_{\alpha}=1-K_{\beta}-K_{\gamma}
$$

The mechanical performance of both non-nucleated $(\mathrm{NN})$ and $\beta$-nucleated (BN) compositions was determined on injection molded bar test specimens of $80 \times 10 \times 4 \mathrm{~mm}^{3}$ prepared following EN ISO 1873-2. Flexural modulus was determined in 3-point-bending at $23^{\circ} \mathrm{C}$ according to ISO 178 , and Charpy notched impact strength (NIS) was measured according to ISO $1791 \mathrm{eA}$ at +23 and $0^{\circ} \mathrm{C}$ on the same sample geometry. All mechanical parameters have been determined according to ISO standards using $10+2$ measurements, discarding the extremes and giving relative standard deviations in the range of $5 \%$. The relative effect of $\beta$-nucleation on impact strength $\left(\Delta_{\mathrm{NIS}}\right)$ was calculated based on the following formula (14):

$\Delta_{\mathrm{NIS}}=\frac{\mathrm{NIS}_{\mathrm{BN}}-\mathrm{NIS}_{\mathrm{NN}}}{\mathrm{NIS}_{\mathrm{NN}}}$

where NIS $\mathrm{BN}_{\mathrm{BN}}$ stands for the value of the $\beta$-nucleated polymer while NIS $\mathrm{NN}_{\mathrm{N}}$ stands for the value of the nonnucleated base polymer. The calculation of $\Delta_{\text {NIS }}$ was done for the values determined at $23^{\circ} \mathrm{C}$.

\section{Results and discussion}

Two methods are commonly applied in both scientific literature and patents for determining the $\beta$-phase content, DSC and WAXS. The main difference is that the former method, using the second heat of the measurement and the distribution between the two endotherms of the modifications, determines rather the possible $\beta$-phase content under slow cooling conditions. While the heating and cooling rate in DSC can be varied in a wider ranger, practically used rates are 5,10 , or $20^{\circ} \mathrm{C} / \mathrm{min}$. In contrast, WAXS measurements are performed either on 'ideal' homogeneous specimens with defined thermal history or specimens from practical conversion processes like extrusion or injection molding. In the latter case, spatial distributions of modifications are the rule rather than the exception $[2,7,73]$, meaning that either averaging or recording with high spatial resolution is required.

In the present study, WAXS was performed on compression molded plaques with a similar cooling history as the DSC samples. Still, Figure 3 shows that the resulting values correlate only roughly, resulting from the fact that the gradual $\beta$-to- $\alpha$-transition in the $2^{\text {nd }}$ DSC heat reduces the recorded $\beta$-phase content depending on its actual amount [74]. In the very $\beta$-phase content range, i.e. for non-nucleated samples, no problems exist. At high content, for $K_{\beta}>$ $80 \%$, the WAXS values are always higher, and the difference has been discussed before as resulting from gradual $\beta$-to- $\alpha$ transformation in the $2^{\text {nd }}$ heating run of the DSC measurement $[5,39]$. Figure 3 does not allow to draw clear conclusions for the middle range of $\beta$-phase content in the absence of a sufficient number of data in that range, but strong nonlinearity as indicated by the dashed line, is at least very likely. For further discussion, the WAXS-based values for $\beta$ - and $\gamma$-phase content will be used only and presented as percentage.

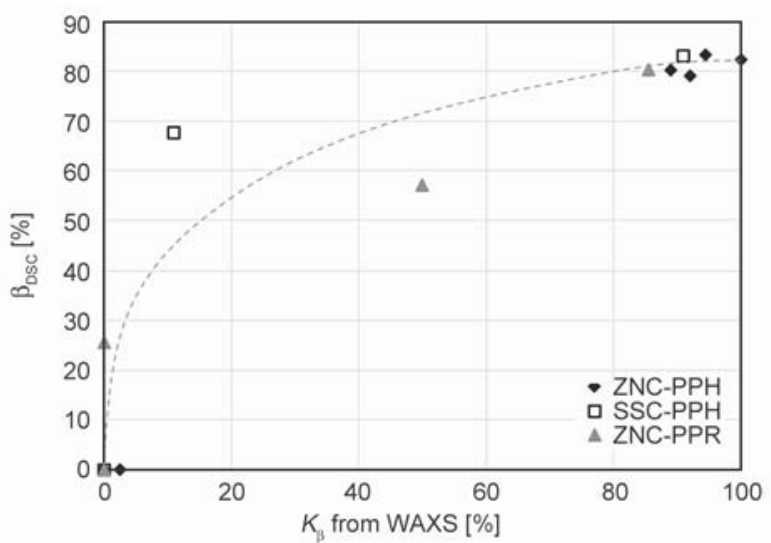

Figure 3. Correlation between WAXS- and DSC-based $\beta$-phase content; calculation based on Equations (6) and (8), dashed line serves only as a guide for the eye. 
Table 2. Compositions and properties of ZNC- and SSC-based iPP homopolymer compositions (nucleating agent concentrations: CGNA-7588 - 0.01 wt $\%$, WBG $-0.21 \mathrm{wt} \%$ ).

\begin{tabular}{|ll|c|c|c|c|c|c|c|c|c|}
\hline \multicolumn{2}{|c|}{ Material } & NN1 & BN1 & BN2 & NN2 & BN3 & BN4 & NN3 & BN5 & BN6 \\
\hline Base & & PP-H1 & PP-H1 & PP-H1 & PP-H2 & PP-H2 & PP-H2 & PP-H3 & PP-H3 & PP-H3 \\
\hline MFR & {$[\mathrm{g} / 10 \mathrm{~min}]$} & 2.8 & 2.8 & 2.8 & 0.3 & 0.3 & 0.3 & 0.4 & 0.4 & 0.4 \\
\hline Nucleation & type & none & CGNA & WBG & none & CGNA & WBG & none & CGNA & WBG \\
\hline$T_{\mathrm{c}}$ & {$\left[{ }^{\circ} \mathrm{C}\right]$} & 116 & 124 & 122 & 120 & 126 & 124 & 115 & 121 & 116 \\
\hline$T_{\mathrm{m}, 1}$ & {$\left[{ }^{\circ} \mathrm{C}\right]$} & 163 & 168 & 168 & 165 & 169 & 169 & 152 & 162 & 153 \\
\hline$T_{\mathrm{m}, 2}$ & {$\left[{ }^{\circ} \mathrm{C}\right]$} & & 152 & 151 & & 152 & 153 & & 148 & 141 \\
\hline$H_{\mathrm{m}, 1}$ & {$[\mathrm{~J} / \mathrm{g}]$} & 96 & 18 & 20.3 & 98 & 16.3 & 19.1 & 96 & 17 & 30.8 \\
\hline$H_{\mathrm{m}, 2}$ & {$[\mathrm{~J} / \mathrm{g}]$} & & 84 & 76.5 & & 81.5 & 77.7 & & 83 & 64.5 \\
\hline$\beta_{\mathrm{DSC}}$ & {$[\%]$} & 0.0 & 82.4 & 79.0 & 0.0 & 83.3 & 80.3 & 0.0 & 83.0 & 67.7 \\
\hline$X_{\mathrm{C}}$ from WAXS & {$[\%]$} & 61.3 & 64.1 & 62.9 & 62.5 & 65.3 & 63.7 & 59.2 & 61.1 & 60.4 \\
\hline$K_{\beta}$ from WAXS & {$[\%]$} & 0.0 & 100.0 & 92.0 & 2.5 & 94.5 & 89.0 & 0.0 & 91.0 & 11.0 \\
\hline$K_{\gamma}$ from WAXS & {$[\%]$} & 0.0 & 0.0 & 0.0 & 0.0 & 1.2 & 3.0 & 22.0 & 2.0 & 25.0 \\
\hline Flexural modulus & {$[\mathrm{MPa}]$} & 1640 & 1570 & 1368 & 1540 & 1360 & 1490 & 1520 & 1609 & 1433 \\
\hline NIS Charpy $23{ }^{\circ} \mathrm{C}$ & {$\left[\mathrm{kJ} / \mathrm{m}^{2}\right]$} & 3.6 & 16.7 & 6.9 & 7.9 & 48 & 27 & 9.5 & 61.2 & 5.1 \\
\hline NIS Charpy $0{ }^{\circ} \mathrm{C}$ & {$\left[\mathrm{kJ} / \mathrm{m}^{2}\right]$} & 1.5 & 2.3 & 2.1 & 2.3 & 4.7 & 4.3 & 2.7 & 3.6 & 2.2 \\
\hline$\Delta_{\text {NIS }}$ & {$[-]$} & - & 3.7 & 0.9 & - & 5.1 & 2.4 & - & 5.4 & -0.5 \\
\hline
\end{tabular}

Table 2 and Figure 4 present the results of nucleation with the two different $\beta$-nucleating agents, including the respective base polymer references of the three iPP homopolymers with different chain structures and molecular weight. As it is difficult to combine isotacticity and region-defects in one number, the $T_{\mathrm{m}}$ (DSC) of the base polymer (NN\#) is used as chain regularity measure in Figure 4 . Of these, the $\beta$-phase content is measurable only for NN2, the PP-H2 having highest isotacticity and molecular weight. In the nucleated samples, a considerably higher $\beta$-phase content was achieved by the 'reference' CGNA7588 , the difference becoming especially pronounced for the SSC-based PP-H3. This is in line with earlier findings $[22,23,45]$, but the strong sensitivity of WBG towards chain defects came as a surprise in view of the most positive literature reports on this substance [20, 21].

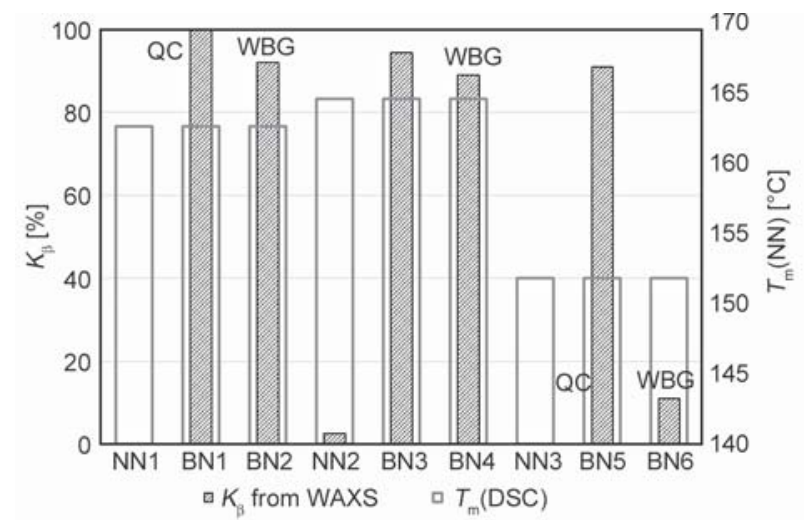

Figure 4. $\beta$-phase content and base polymer melting point of ZNCand SSC-based iPP homopolymer compositions.
Similar effects were also found for the ethylenepropylene random copolymers (iPP-RACOs), the results being presented in Table 3 and Figure 5. As no $\beta$-phase formation was found with WBG in PP-R1, a second RACO with lower ethylene content but similar molecular weight was selected, in which at least a limited nucleation effect could be observed. For this type of iPP grades, the problem of the increased sensitivity of WBG has been studied before [11] and is clearly limiting applicability.

Table 3. Compositions and properties of ZNC-based iPPRACO compositions (nucleating agent concentrations: CGNA-7588 - 0.01 wt $\%, \mathrm{WBG}-0.21 \mathrm{wt} \%)$.

\begin{tabular}{|c|c|c|c|c|}
\hline Material & NN4 & BN7 & BN8 & BN9 \\
\hline Base & PP-R1 & PP-R1 & PP-R1 & PP-R2 \\
\hline$[\mathrm{g} / 10 \mathrm{~min}]$ & 1.9 & 1.9 & 1.9 & 2.0 \\
\hline Nucleation & none & CGNA & WBG & WBG \\
\hline$\left[{ }^{\circ} \mathrm{C}\right]$ & 114 & 109 & 104 & 110 \\
\hline$\left[{ }^{\circ} \mathrm{C}\right]$ & 149 & 151 & 147 & 152 \\
\hline$\left[{ }^{\circ} \mathrm{C}\right]$ & 136 & 135 & & 140 \\
\hline$[\mathrm{J} / \mathrm{g}]$ & 64.5 & 15.8 & 80.2 & 39 \\
\hline$[\mathrm{J} / \mathrm{g}]$ & 22.1 & 64.1 & & 52 \\
\hline$\beta_{\mathrm{DSC}}$ & 25.5 & 80.2 & 0.0 & 57.1 \\
\hline$X_{\mathrm{C}}$ from WAXS $[\%]$ & 58.5 & 60.5 & 59.1 & 61.2 \\
\hline$K_{\beta}$ from WAXS $[\%]$ & 0 & 85.5 & 0.0 & 50.0 \\
\hline$K_{\gamma}$ from WAXS $\quad[\%]$ & 12.3 & 3.5 & 4.2 & 5.2 \\
\hline Flexural modulus [MPa] & 1120 & 935 & 931 & 1072 \\
\hline NIS Charpy $23^{\circ} \mathrm{C}\left[\mathrm{kJ} / \mathrm{m}^{2}\right]$ & 9.5 & 12.5 & 7.2 & 6.9 \\
\hline NIS Charpy $0{ }^{\circ} \mathrm{C} \quad\left[\mathrm{kJ} / \mathrm{m}^{2}\right]$ & 2.6 & 2.5 & 1.8 & 2.1 \\
\hline$\Delta_{\mathrm{NIS}}$ & - & 0.3 & -0.2 & n.d. \\
\hline
\end{tabular}




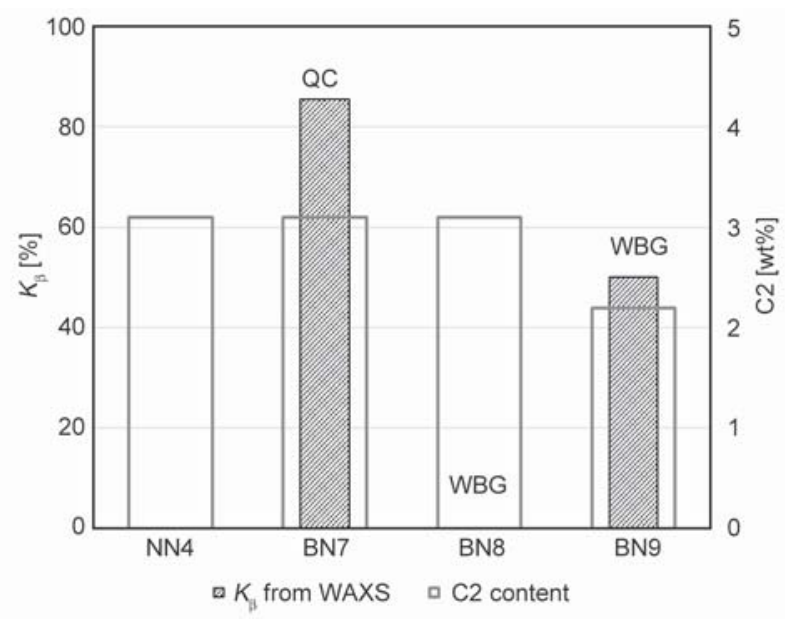

Figure 5. $\beta$-phase content and base polymer melting point of ZNC-based iPP-RACO compositions.

Tables 2 and 3 also list the resulting mechanical performance of all compositions, showing a significant toughness increase, which is the main target of iPP $\beta$-nucleation [2, 5, 27, 42]. As Figure 6 shows, there is no clear correlation between the overall toughness at ambient temperature (as expressed by the Charpy notched impact strength at $23^{\circ} \mathrm{C}$ ) and the $K_{\beta}$ from WAXS. The diagram shows significant scatter at a $\beta$-phase content of more than $80 \%$, partly resulting from the strong molecular weight effect explained earlier [5, 43]. In addition to that, for PP-H1 and PP$\mathrm{H} 2$ the seemingly small difference in nucleation efficiency between CGNA-7588 and WBG results in a much more significant impact strength difference. While the limited impact resistance of the WBG-nucleated PP-H3 and PP-R2 can still be explained by the also limited $\beta$-phase content, the massive variation in the range $>80 \%$ must be related to other effects as well.

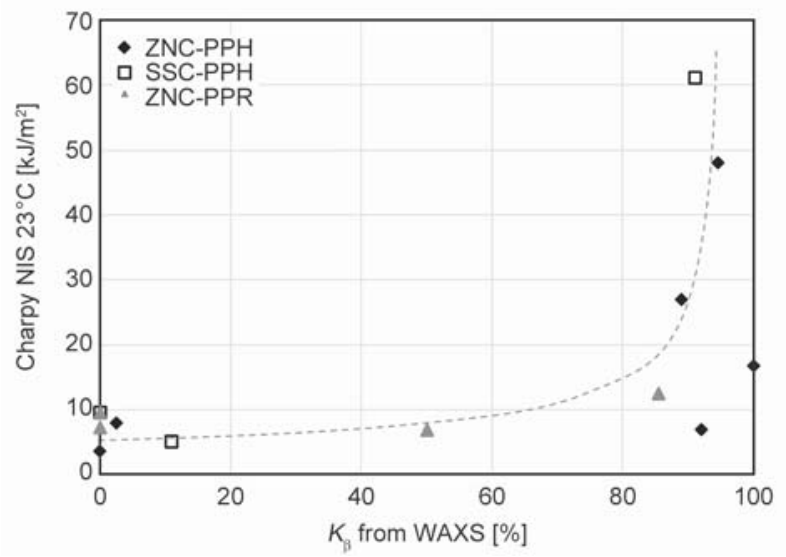

Figure 6. Correlation between $\beta$-phase content and impact resistance of all investigated compositions, the dashed line serves only as guide for the eye.

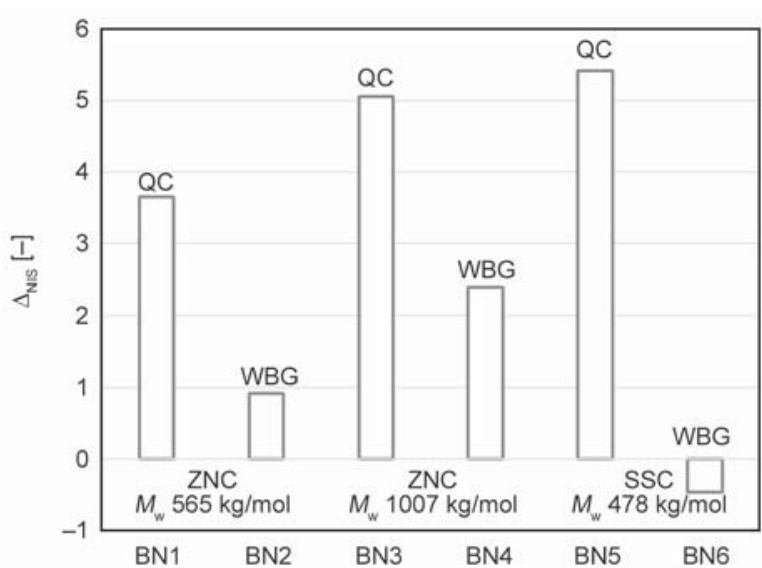

Figure 7. $\beta$-nucleation effect on impact strength expressed as $\Delta_{\mathrm{NIS}}$ for ZNC- and SSC-based iPP homopolymers

In order to exclude the molecular weight effect, which is also present for the impact resistance of non-nucleated iPP homopolymers [62], the relative value of $\Delta_{\text {NIS }}$ can be calculated by Equation (14). As Figure 7 shows, even in the worst-case increases by $300 \%$ can be achieved with CGNA-7588, while at least for the SSC-PPH a negative effect results from nucleation with WBG. Taking a look at Table 3, one realizes that the formation of $\gamma$-phase is increased from 22 to $25 \%$ for this composition (BN6), meaning that WBG might show some duality as also observed for DCHT [21]. The effect is less expressed for PP-R2 with a $\gamma$-phase content of 5.2\% (up from $4.2 \%$ ), and also here the resulting impact strength is very low. For $\alpha$-nucleating agents, the ability of some types to also promote $\gamma$-phase formation in SSC-PPH [22] or ZNC-RACOs [2, 48] has been demonstrated and explained before. We, therefore, assume that an $\alpha / \beta$-nucleation duality of WBG (as observed for DCHT [21]) could indeed be expected to have such effects.

\section{Conclusions}

The negative effects of iPP chain irregularity resulting from stereo- and regiodefects [45] or comonomer insertion $[11,60]$ on the efficiency of $\beta$-nucleating agents are confirmed in all series. Independent of molecular weight, the differences in $\beta$-phase content are less expressed than the ones in impact strength, either resulting from additional processing effects $[2$, $5]$ or from morphological variations. Effective $\beta$-nucleation of SSC-based iPP homopolymers or random copolymers, in general, requires more attention and the selection of stable compositions. 
Between the 'reference' type of $\beta$-nucleating agent quinacridonequinone CGNA-7588 and the heteronuclear dimetal complex of lanthanum and calcium WBG there is a clear difference in efficiency and sensitivity. The $0.01 \mathrm{wt} \%$ of CGNA-7588 based on experience was found to be satisfactory. Despite the fact that with $0.21 \mathrm{wt} \%$ a concentration of WBG was chosen, which was assumed to be 'safe' and clearly in the saturation range in terms of $\beta$-phase formation according to literature $[12,14]$, the higher sensitivity towards chain regularity of iPP as well as the more limited impact strength increase (see Figure 5) are evident. The results from compositions based on SSC-PPH and ZNC-RACO indicate some $\beta / \alpha$-duality of WBG, actually resulting in an increase of $\gamma$-phase content and a rather low impact strength.

More work in the direction of chain irregularities, including a variation of stereo- vs. regiodefects and possibly a combination of the same with molecular weight changes would definitely be of interest. In that respect, the sensitivity of other $\beta$-nucleating agents like Ca-pimelate or $\mathrm{Zn}$-adipate to such changes should be considered as well.

\section{References}

[1] Mileva D., Tranchida D., Gahleitner M.: Designing polymer crystallinity: An industrial perspective. Polymer Crystallisation, 1, e10009/1-e10009/16 (2018). https://doi.org/10.1002/pcr2.10009

[2] Gahleitner M., Mileva D., Androsch R., Gloger D., Tranchida D., Sandholzer M., Doshev P.: Crystallinitybased product design: Utilizing the polymorphism of isotactic PP homo- and copolymers. International Polymer Processing, 23, 618-627 (2016).

https://doi.org/10.3139/217.3242

[3] Lotz B.: Frustration and frustrated crystal structures of polymers and biopolymers. Macromolecules, 45, 21752189 (2012).

https://doi.org/10.1021/ma202326t

[4] Stocker W., Schumacher M., Graff S., Thierry A., Wittmann J-C., Lotz B.: Epitaxial crystallization and AFM investigation of a frustrated polymer structure: Isotactic poly(propylene), $\beta$ phase. Macromolecules, 31, 807-814 (1998).

https://doi.org/10.1021/ma971345d

[5] Grein C.: Toughness of neat, rubber modified and filled $\beta$-nucleated polypropylene: From fundamentals to applications. Advances in Polymer Science, 188, 43-104 (2005).

https://doi.org/10.1007/b136972

[6] Gahleitner M., Grein C., Kheirandish S., Wolfschwenger J.: Nucleation of polypropylene homo- and copolymers. International Polymer Processing, 26, 2-20 (2011).

https://doi.org/10.3139/217.2411
[7] Liu Z., Liu X., Li L., Zheng G., Liu C., Qin Q., Mi L.: Crystalline structure and remarkably enhanced tensile property of $\beta$-isotactic polypropylene via overflow microinjection molding. Polymer Testing, 76, 448-454 (2019). https://doi.org/10.1016/j.polymertesting.2019.04.002

[8] Yi Q-F., Wen X-J., Dong J-Y., Han C. C.: A novel effective way of comprising a $\beta$-nucleating agent in isotactic polypropylene (i-PP): Polymerized dispersion and polymer characterization. Polymer, 49, 5053-5063 (2008).

https://doi.org/10.1016/j.polymer.2008.09.037

[9] Luo F. Geng C., Wang K., Deng H., Chen F., Fu Q., Na B.: New understanding in tuning toughness of $\beta$-polypropylene: The role of $\beta$-nucleated crystalline morphology. Macromolecules, 42, 9325-9331 (2009). https://doi.org/10.1021/ma901651f

[10] Luo F., Wang J., Bai H., Wang K., Deng H., Zhang Q., Chen F., Fu Q., Na B.: Synergistic toughening of polypropylene random copolymer at low temperature: $\beta$-modification and annealing. Materials Science and Engineering: A, 528, 7052-7059 (2011). https://doi.org/10.1016/j.msea.2011.05.030

[11] Luo F., Zhu Y., Wang K., Deng H., Chen F., Zhang Q., Fu Q.: Enhancement of $\beta$-nucleated crystallization in polypropylene random copolymer via adding isotactic polypropylene. Polymer, 53, 4861-4870 (2012). https://doi.org/10.1016/j.polymer.2012.08.037

[12] Zhang Y., Sun T., Jiang W., Han G.: Crystalline modification of a rare earth nucleating agent for isotactic polypropylene based on its self-assembly. Royal Society Open Science, 5, 180247/1-180247/10 (2018) https://doi.org/10.1098/rsos.180247

[13] Jiang X., Yu Y., Xu R., Li L., Cao Y., Xiang M., Kang J., Sheng X.: Effects of stereo-defect distribution on the crystallization and polymorphic behavior of $\beta$-nucleated isotactic polypropylene/graphene oxide composites with different melt structures. Polymer Engineering and Science, 59, 1097-1104 (2019). https://doi.org/10.1002/pen.25086

[14] Xiong F., Guan R., Xiao Z., Xiang B., Lu D.: Influence of $\beta$-nucleators on iPP crystallization and morphology. Polymer-Plastics Technology and Engineering, 46, 97103 (2007). https://doi.org/10.1080/03602550601152739

[15] Wei Z., Zhang W., Chen G., Liang J., Yang S., Wang P., Liu L.: Crystallization and melting behavior of isotactic polypropylene nucleated with individual and compound nucleating agents. Journal of Thermal Analysis and Calorimetry, 102, 775-783 (2010). https://doi.org/10.1007/s10973-010-0725-9

[16] Luo F., Xu C., Wang K., Deng H., Chen F., Fu Q.: Exploring temperature dependence of the toughening behavior of $\beta$-nucleated impact polypropylene copolymer. Polymer, 53, 1783-1790 (2012). https://doi.org/10.1016/j.polymer.2012.02.024 
[17] Jiang Q., Jia H., Wang J., Fang E., Jiang J.: Effects of nucleating agents on crystallization behavior and mechanical properties of high-fluid polypropylene. Iranian Polymer Journal, 21, 201-209 (2012). https://doi.org/10.1007/s13726-012-0024-3

[18] He J., Zhang Y-F., Ren X-Q., Li Y.: Nucleation effect of $\alpha / \beta$ compound nucleating agents based on $1,3,5$-benzenetricarboxylic acid tris(cyclohexylamide) in isotactic polypropylene. Polymer Bulletin, 76, 5559-5575 (2019). https://doi.org/10.1007/s00289-018-02671-1

[19] Xiao W., Wu P., Feng J.: Effect of $\beta$-nucleating agents on crystallization and melting behavior of isotactic polypropylene. Journal of Applied Polymer Science, 108, 3370-3379 (2008).

https://doi.org/10.1002/app.27997

[20] Fu J., Li X., Zhou M., Hong R., Zhang J.: The $\alpha-, \beta-$, and $\gamma$-polymorphs of polypropylene-polyethylene random copolymer modified by two kinds of $\beta$-nucleating agent. Polymer Bulletin, 76, 865-881 (2019).

https://doi.org/10.1007/s00289-018-2413-Z

[21] Varga J., Menyhárd A.: Effect of solubility and nucleating duality of $N, N^{\prime}$-dicyclohexyl-2,6-naphthalenedicarboxamide on the supermolecular structure of isotactic polypropylene. Macromolecules, 40, 2422-2431 (2007). https://doi.org/10.1021/ma062815j

[22] Busse K., Kressler J., Maier R-D., Scherble J.: Tailoring of the $\alpha-, \beta$-, and $\gamma$-modification in isotactic polypropene and propene/ethene random copolymers. Macromolecules, 33, 8775-8780 (2000).

https://doi.org/10.1021/ma000719r

[23] Varma-Nair M., Agarwal P. K.: Quiesent crystallization kinetics of nucleated metallocene and $\mathrm{ZN}$ isotactic polypropylenes. Journal of Thermal Analysis and Calorimetry, 59, 483-495 (2000).

https://doi.org/10.1023/A:1010145625770

[24] Wang Z., Yang W., Liu G., Müller A. J., Zhao Y., Dong X., Wang Z., Wang D.: Probing into the epitaxial crystallization of $\beta$ form isotactic polypropylene: From experimental observations to molecular mechanics computation. Journal of Polymer Science B: Polymer Physics, 55, 418-424 (2017).

https://doi.org/10.1002/polb.24293

[25] Wang N., Niu H., Li Y.: A novel catalytic way of comprising a $\beta$-nucleating agent in isotactic polypropylene: Catalyst design strategy and polymerization-assisted dispersion. Polymer, 113, 259-266 (2017). https://doi.org/10.1016/j.polymer.2017.02.075

[26] Monami A., Langer B., Sadlek J., Kučera J., Grellmann W.: Mechanical and fracture mechanical properties of polymorphous polypropylene. in 'Deformation and fracture behaviour of polymer materials' (eds.: Grellmann W., Langer B.) Springer, Berlin, 73-81 (2017). https://doi.org/10.1007/978-3-319-41879-7 5
[27] Chen Y., Wu Z., Fan Q., Yang S., Song E., Zhang Q.: Great toughness reinforcement of isotactic polypropylene/elastomer blends with quasi-cocontinuous phase morphology by traces of $\beta$-nucleating agents and carbon nanotubes. Composites Science and Technology, 167, 277-284 (2018).

https://doi.org/10.1016/j.compscitech.2018.08.015

[28] Niu H., Wang N., Li Y.: Influence of $\beta$-nucleating agent dispersion on the crystallization behavior of isotactic polypropylene. Polymer, 150, 371-379 (2018). https://doi.org/10.1016/j.polymer.2018.07.030

[29] Wang G., Hou S., Cao J., Ding P., Shen J., Chen J.: Reinforcing and toughening isotactic polypropylene through shear-induced crystallization and $\beta$-nucleating agent induced crystallization. Journal of Polymer Research, 25, 233/1-233/8 (2018).

https://doi.org/10.1007/s10965-018-1632-1

[30] Dong M., Xu Y. H., Zhang S. J., Xu K., Zhang L. Y., Lv Y., Bai Y. Q., Chen R. S.: An effective $\alpha / \beta$ nucleating agent compound for the preparation of polypropylene. International Polymer Processing, 33, 164-170 (2018). https://doi.org/10.3139/217.3361

[31] Kurihara H., Kitade S., Ichino K., Akiba I., Sakurai K.: Elongation induced $\beta$ - to $\alpha$-crystalline transformation and microvoid formation in isotactic polypropylene as revealed by time-resolved WAXS/SAXS. Polymer Journal, 51, 199-209 (2019).

https://doi.org/10.1038/s41428-018-0141-8

[32] Chvátalova L., Navrátilova J., Čermak R., Raab M., Obadal M.: Joint effects of molecular structure and processing history on specific nucleation of isotactic polypropylene. Macromolecules, 42, 7413-7417 (2009). https://doi.org/10.1021/ma9005878

[33] Cui L., Wang P., Zhang Y., Zhou X., Xu L., Zhang L., Zhang L., Liu L., Guo X.: Glass fiber reinforced and $\beta$-nucleating agents regulated polypropylene: A complementary approach and a case study. Journal of Applied Polymer Science, 135, 45768/1-45768/9 (2018). https://doi.org/10.1002/APP.45768

[34] Cui L., Wang P., Zhang Y., Zhang L., Chen Y., Wang L., Liu L., Guo X.: Combined effect of $\alpha$-nucleating agents and glass fiber reinforcement on a polypropylene composite: A balanced approach. RSC Advances, 7, 42783/1-42783/10 (2017). https://doi.org/10.1039/c7ra08322j

[35] Lustiger A., Marzinsky C. N., Mueller R. R., Wagner H. D.: Morphology and damage mechanisms of the transcrystalline interphase in polypropylene. Journal of Adhesion, 53, 1-14 (1995). https://doi.org/10.1080/00218469508014368

[36] Assouline E., Pohl S., Fulchiron R., Gérard J-F., Lustiger A., Wagner H. D., Marom G.: The kinetics of $\alpha$ and $\beta$ transcrystallization in fibre-reinforced polypropylene. Polymer, 41, 7843-7854 (2000). https://doi.org/10.1016/S0032-3861(00)00113-0 
[37] Sterzynski T., Lambla M., Georgi F., Thomas M.: Studies of the trans-quinacridone nucleation of poly-(ethylene- $b$-propylene). International Polymer Processing, 12, 64-71 (1997).

https://doi.org/10.3139/217.970064

[38] Sterzynski T., Calo P., Lambla M., Thomas M.: Transand dimethyl quinacridone nucleation of isotactic polypropylene. Polymer Engineering and Science, 37, 1917 1927 (1997). https://doi.org/10.1002/pen.11842

[39] Mollova A., Androsch R., Mileva D., Gahleitner M., Funari S. S.: Crystallization of isotactic polypropylene containing beta-phase nucleating agent at rapid cooling. European Polymer Journal, 49, 1057-1065 (2013). https://doi.org/10.1016/j.eurpolymj.2013.01.015

[40] Barczewski M., Matykiewicz D., Hoffmann B.: Effect of quinacridone pigments on properties and morphology of injection molded isotactic polypropylene. International Journal of Polymer Science, 2017, 7043297/17043297/8 (2017). https://doi.org/10.1155/2017/7043297

[41] Gohn A. M., Rhoades A. M., Okonski D., Androsch R.: Effect of melt-memory on the crystal polymorphism in molded isotactic polypropylene. Macromolecular Materials and Engineering, 303, 1800148/1-1800148/7 (2018). https://doi.org/10.1002/mame.201800148

[42] Chen H. B., Karger-Kocsis J., Wu J. S., Varga J.: Fracture toughness of $\alpha$ - and $\beta$-phase polypropylene homopolymers and random- and block-copolymers. Polymer, 43, 6505-6514 (2002).

https://doi.org/10.1016/S0032-3861(02)00590-6

[43] Grein C., Gahleitner M.: On the influence of nucleation on the toughness of iPP/EPR blends with different rubber molecular architectures. Express Polymer Letters, 2, 392-397 (2008).

https://doi.org/10.3144/expresspolymlett.2008.47

[44] Yue Y., Hu D., Zhang Q., Lin J., Feng J.: The effect of structure evolution upon heat treatment on the beta-nucleating ability of calcium pimelate in isotactic polypropylene. Polymer, 149, 55-64 (2018).

https://doi.org/10.1016/j.polymer.2018.06.060

[45] Krache R., Benavente R., López-Majada J. M., Pereña J. M., Cerrada M. L., Pérez E.: Competition between $\alpha$, $\beta$, and $\gamma$ polymorphs in a $\beta$-nucleated metallocenic isotactic polypropylene. Macromolecules, 40, 6871-6878 (2007)

https://doi.org/10.1021/ma0710636

[46] Chen Z., Kang W., Kang J., Chen J., Yang F., Cao Y., Xiang M.: Non-isothermal crystallization behavior and melting behavior of Ziegler-Natta isotactic polypropylene with different stereo-defect distribution nucleated with bi-component $\beta$-nucleation agent. Polymer Bulletin, 72, 3283-3303 (2015).

https://doi.org/10.1007/s00289-015-1466-5
[47] Zhang Z., Tao Y., Yang Z., Mai K.: Preparation and characteristics of nano- $\mathrm{CaCO}_{3}$ supported $\beta$-nucleating agent of polypropylene. European Polymer Journal, 44, 1955-1961 (2008).

https://doi.org/10.1016/j.eurpolymj.2008.04.022

[48] Horváth Zs., Sajó I. E., Stoll K., Menyhárd A., Varga J.: The effect of molecular mass on the polymorphism and crystalline structure of isotactic polypropylene. Express Polymer Letters, 4, 101-114 (2010). https://doi.org/10.3144/expresspolymlett.2010.15

[49] Varga J., Mudra I., Ehrenstein G. W.: Highly active thermally stable $\beta$-nucleating agents for isotactic polypropylene. Journal of Applied Polymer Science, 74, 2357-2368 (1999).

https://doi.org/10.1002/(SICI)10974628(19991205)74:10<2357::AID-APP3>3.0.CO;2-2

[50] Varga J., Stoll K., Menyhárd A., Horváth Z.: Crystallization of isotactic polypropylene in the presence of a $\beta$-nucleating agent based on a trisamide of trimesic acid. Journal of Applied Polymer Science, 121, 14691480 (2011). https://doi.org/10.1002/app.33685

[51] Yang R., Ding L., Chen W., Chen L., Zhang X., Li J.: Chain folding in main-chain liquid crystalline polyester with strong $\pi-\pi$ interaction: An efficient $\beta$-nucleating agent for isotactic polypropylene. Macromolecules, 50, 6010-6017 (2017). https://doi.org/10.1021/acs.macromol.6b02521

[52] Zhao S., Gong H., Yu X., Xin Z., Sun S., Zhou S., Shi $Y$.: A highly active and selective $\beta$-nucleating agent for isotactic polypropylene and crystallization behavior of $\beta$-nucleated isotactic polypropylene under rapid cooling. Journal of Applied Polymer Science, 133, 43767/143767/9 (2016).

https://doi.org/10.1002/APP.43767

[53] Pan C., Qin W., Chen L., Xin Z., Zhao S., Ye C.: A novel $\beta$-nucleating agent for isotactic polypropylene. Journal of Thermal Analysis and Calorimetry, 134, 2029-2040 (2018). https://doi.org/10.1007/s10973-018-7768-8

[54] Liu X., Liu Y., Fang Y., Zhu D., Wang X., Yang B.: Improving the impact strength of polypropylene/carbon fiber composites via $\beta$-modification and annealing treatment. Polymer Crystallization, 1, e10010/1- e10010/11 (2018). https://doi.org/10.1002/pcr2.10010

[55] Liu S., Yang J., Liu Q., Huang Y., Kong M., Yang Q., Li G.: Polydopamine particles as a $\beta$-nucleating agent and antioxidant for isotactic polypropylene. Chemical Engineering Journal, 363, 1-12 (2019). https://doi.org/10.1016/j.cej.2019.01.118

[56] Gahleitner M., Jääskeläinen P., Ratajski E., Paulik C., Reussner J., Wolfschwenger J., Neiß1 W.: Propyleneethylene random copolymers: Comonomer effects on crystallinity and application properties. Journal of Applied Polymer Science, 95, 1073-1081 (2005). https://doi.org/10.1002/app.21308 
[57] Horváth Z., MenyhÁrd A., Doshev P., Gahleitner M., Vörös G., Varga J., Pukánszky B.: Effect of the molecular structure of the polymer and nucleation on the optical properties of polypropylene homo- and copolymers. ACS Applied Materials and Interfaces, 6, 74567463 (2014).

https://doi.org/10.1021/am5008535

[58] De Rosa C., Auriemma F., Vollaro P., Resconi L., Guidotti S., Camurati I.: Crystallization behavior of propylene-butene copolymers: The trigonal form of isotactic polypropylene and form I of isotactic poly(1butene). Macromolecules, 44, 540-549 (2011).

https://doi.org/10.1021/ma102534f

[59] Cavallo D., Gardella L., Alfonso G. C., Mileva D., Androsch R.: Effect of comonomer partitioning on the kinetics of mesophase formation in random copolymers of propene and higher $\alpha$-olefins. Polymer, 53, 44294437 (2012).

https://doi.org/10.1016/j.polymer.2012.08.001

[60] Varga J., Schulek-Tóth F.: Crystallization, melting and spherulitic structure of $\beta$-nucleated random propylene copolymers. Journal of Thermal Analysis, 47, 941-955 (1996).

https://doi.org/10.1007/BF01979441

[61] Fujiyama M.: Structure and properties of injection moldings of $\beta$-crystal nucleator-added PP. International Polymer Processing, 13, 291-298 (1998).

https://doi.org/10.3139/217.980291

[62] Gahleitner M., Bachner C., Ratajski E., Rohaczek G., Neiß1 W.: Effects of the catalyst system on the crystallization of polypropylene. Journal of Applied Polymer Science, 73, 2507-2515 (1999).

https://doi.org/10.1002/(SICI)10974628(19990919)73:12<2507::AID-APP19>3.0.CO;2-V

[63] Gahleitner M., Tranninger C., Doshev P.: Heterophasic copolymers of polypropylene: Development, design principles, and future challenges. Journal of Applied Polymer Science, 130, 3028-3037 (2013).

https://doi.org/10.1002/app.39626

[64] Vestberg T., Parkinson M., Fonseca I., Wilén C-E.: Poly(propylene-co-ethylene) produced with a conventional and a self-supported ziegler-natta catalyst: Effect of ethylene and hydrogen concentration on activity and polymer structure. Journal of Applied Polymer Science, 124, 4889-4896 (2012).

https://doi.org/10.1002/app.35586

[65] Busico V., Cipullo R.: Microstructure of polypropylene. Progress in Polymer Science, 26, 443-533 (2001).

https://doi.org/10.1016/S0079-6700(00)00046-0
[66] Zhou Z., Kümmerle R., Qiu X., Redwine D., Cong R., Taha A., Baugh D. Winniford B.: A new decoupling method for accurate quantification of polyethylene copolymer composition and triad sequence distribution with ${ }^{13} \mathrm{C}$ NMR. Journal of Magnetic Resonance, 187, 225-233 (2007).

https://doi.org/10.1016/j.jmr.2007.05.005

[67] Busico V., Cipullo R., Monaco G., Vacatello M., Segre A. L.: Full assignment of the ${ }^{13} \mathrm{C}$ NMR spectra of regioregular polypropylenes: Methyl and methylene region. Macromolecules, 30, 6251-6263 (1997). https://doi.org/10.1021/ma970466a

[68] Resconi L., Cavallo L., Fait A., Piemontesi F.: Selectivity in propene polymerization with metallocene catalysts. Chemical Reviews, 100, 1253-1346 (2000). https://doi.org/10.1021/cr9804691

[69] Challa G., Hermans P. H., Weidinger A.: On the determination of the crystalline fraction in isotactic polystyrene from X-ray diffraction. Die Makromolekulare Chemie, 56, 169-178 (1962).

https://doi.org/10.1002/macp.1962.020560112

[70] Turner-Jones A., Aizlewood J. M., Beckett D. R.: Crystalline forms of isotactic polypropylene. Die Makromolekulare Chemie, 75, 134-158 (1974).

https://doi.org/10.1002/macp.1964.020750113

[71] Pae K. D.: $\gamma-\alpha$ Solid-solid transition of isotactic polypropylene. Journal of Polymer Science A-2: Polymer Physics, 6, 657-663 (1968).

https://doi.org/10.1002/pol.1968.160060401

[72] Obadal M., Čermák R., Stoklasa K.: Tailoring of threephase crystalline systems in isotactic poly(propylene). Macromolecular Rapid Communications, 26, 12531257 (2005). https://doi.org/10.1002/marc.200500272

[73] Moitzi J., Skalicky P.: Shear-induced crystallization of isotactic polypropylene melts: Isothermal WAXS experiments with synchrotron radiation. Polymer 34, 1253-1257 (1993). https://doi.org/10.1016/0032-3861(93)90385-N

[74] Zhou G-E., He Z-Q., Yu J-M., Han Z-W., Shi G-Y.: Studies on the $\beta$-form of isotactic polypropylene, 1 . Characterization of the $\beta$-form and study of the $\beta-\alpha$ transition during heating by wide angle X-ray diffraction. Die Makromolekulare Chemie, 187, 633-642 (1986). https://doi.org/10.1002/macp.1986.021870315 